\title{
Serum 25-hydroxyvitamin $D$ concentrations are associated with erythrocyte levels of $n-3$ PUFA but not risk of CVD
}

\author{
Yongsoon Park* and Minkyung Kim \\ Department of Food and Nutrition, College of Human Ecology, Hanyang University, 17 Haengdang-dong, Seongdong-gu, \\ Seoul 133-791, South Korea \\ (Received 7 October 2010 - Revised 21 January 2011 - Accepted 14 March 2011 - First published online 1 June 2011)
}

\section{Abstract}

Increasing evidence suggests that the status of vitamin D and $n-3$ PUFA is associated with the risk of CVD. Major dietary sources of vitamin D include fish and fish products, which are also rich in $n-3$ PUFA; however, the relationship between serum 25 -hydroxyvitamin D levels and tissue contents of $n$-3 PUFA remains unknown. The present study investigates the hypothesis that serum 25 -hydroxyvitamin D and erythrocyte $n-3$ PUFA levels are positively correlated in patients with CVD. We recruited sixty CVD cases and matched them with sixty healthy controls based on age, sex and season during which blood was drawn for the study. As serum 25-hydroxyvitamin D levels increased, erythrocyte levels of docosapentaenoic acid, DHA, omega- 3 index and total $n-3$ PUFA increased significantly, while erythrocyte levels of stearic acid and total SFA decreased significantly, after adjusting for age, sex, BMI and smoking. Partial correlation analysis also showed that erythrocyte $n$-3 PUFA levels were positively correlated $(r 0.215 ; P=0.021)$ and total SFA content was negatively correlated $(r-0.263 ; P=0.004)$ with serum 25-hydroxyvitamin D levels. However, multiple logistic regression analysis showed that serum 25-hydroxyvitamin D levels were not significantly associated with the risk of CVD, after adjusting or not adjusting for age, sex, BMI and smoking. In conclusion, the results of our case-control study suggest that serum 25-hydroxyvitamin D levels are positively related to erythrocyte $n$-3 PUFA levels, but are not associated with the risk of CVD in this population.

Key words: Serum 25-hydroxyvitamin D: Erythrocyte fatty acid composition: CVD

Interest in vitamin $\mathrm{D}$ has intensified lately, with a growing body of evidence suggesting that adequate vitamin D status is required for optimal health ${ }^{(1,2)}$. The vitamin $\mathrm{D}$ axis affects vascular smooth muscle cell proliferation, inflammation, vascular calcification, the renin-angiotensin system and blood pressure, all of which affect risk of $\mathrm{CVD}^{(3)}$. The Health Professionals Follow-up Study ${ }^{(4)}$, Min-Finland Health Study ${ }^{(5)}$, and Ludwigshafen Risk and Cardiovascular Health Study ${ }^{(6)}$ indicate that low vitamin D levels are associated with an increased risk of CVD. However, the Third National Health and Nutrition Examination Survey ${ }^{(7,8)}$ reported no association between vitamin D status and the risk of CVD, and the Women's Health Initiative trial ${ }^{(9,10)}$ observed that vitamin D supplementation did not decrease the incidence and mortality of CVD. Thus, studies regarding the relationship between vitamin $\mathrm{D}$ and CVD are inconclusive at this point.

A major source of vitamin $\mathrm{D}$ is endogenous production via the action of the sun's UV-B rays on the 7-dehydrocholesterol precursor in the skin, which is then converted to vitamin D. Vitamin D undergoes 25-hydroxylation in the liver to form 25-hydroxyvitamin $\mathrm{D}$, the metabolite that reflects stores of vitamin D. Few foods naturally contain vitamin D and oily fish, such as salmon, sardines, mackerel and tuna, are good sources of vitamin $\mathrm{D}^{(1)}$. Oily fish contain not only vitamin $\mathrm{D}$, but also long-chain n-3 PUFA, EPA, 20:5n3 and DHA, 22:6n3. Higher fish intake and erythrocyte EPA and DHA levels ${ }^{(11)}$ have been shown to be a significant and independent discriminator of $\mathrm{CVD}^{(12,13)}$. The Diet and Reinfarction Trial $^{(14)}$, Gruppo Italiano per lo Studio della Sopravvivenza nell'Infarto Miocardico-Prevenzione (Italian Group for the Study of the Survival of Myocardial Infarction) ${ }^{(15)}$, and the Japan EPA Lipid Intervention Study ${ }^{(16)}$, have shown that oily fish, EPA and DHA and EPA alone significantly reduce cardiac death.

The Korean population consumes greater amounts of fish (average consumption $67 \cdot 7 \mathrm{~g} / \mathrm{d}$ ) ${ }^{(17)}$ than most Western populations, and therefore Koreans tend to have higher tissue $n-3$ PUFA levels ${ }^{(12,13-18)}$, which may be positively correlated with serum 25-hydroxyvitmain D levels. In the present study, we investigated the hypothesis that tissue levels of $n-3$ PUFA are positively associated with 25-hydroxyvitamin $\mathrm{D}$ levels, and 25-hydroxyvitamin D levels are independently associated with the risk for CVD in Koreans with and without a first event of CVD, after adjusting for other risk factors. 


\section{Experimental methods}

\section{Subjects}

Subjects were recruited consecutively from among patients admitted to Hanyang University Seoul Hospital between May 2007 and May 2009. Cases consisted of patients diagnosed with first-event myocardial infarction or stroke ( $n$ 60), and controls ( $n$ 60) were matched by age, sex, season during which blood was drawn and BMI. Patients were excluded if they had a history of CVD, cancer, hyperlipidaemia or diabetes. The present study was conducted according to the guidelines laid out in the Declaration of Helsinki and all procedures involving human subjects were approved by the Institutional Review Board of Hanyang University Seoul Hospital. Written informed consent was obtained from all participants. Anthropometric data, medical history and socioeconomic status were obtained by medical chart reviews and interviews. 'Drinker' was defined by drinking more than a glass a month during the last year, 'current smoker' meant currently smoking and smoking more than five packs in the lifetime, and 'exercise' meant more than three times a week of exercising for at least $20 \mathrm{~min}$.

\section{Laboratory measurements}

Blood samples were collected in EDTA and SST (serum separated tube) blood collection tubes on the day of admission. The samples were centrifuged and divided into aliquots for storage at $-80^{\circ} \mathrm{C}$. Serum lipid profiles (TBA-30FR; Toshiba, Tokyo, Japan), blood chemicals (Coulter LH 750; Beckman Coulter, Inc., Fullerton, CA, USA), liver function (Variant II; Bio-Rad, Hercules, CA, USA) and C-reactive protein concentrations (IMMAGE Immunochemistry System; Beckman Coulter, Inc.) were measured with auto analysers. Levels of IL- 6 and TNF- $\alpha$ were measured at $490 \mathrm{~nm}$ with an ELISA reader (E max precision Molecular Device Company, Sunnyvale, CA, USA) using commercially available high-sensitivity ELISA kits (R\&D Systems, Inc., Minneapolis, MN, USA). Mean COefficients of variation for IL-6 were $7 \cdot 8$ and $6 \cdot 5 \%$ at levels of 2.45 and $5.65 \mathrm{pg} / \mathrm{ml}$, respectively. For TNF- $\alpha$, the CV were 8.5 and $10.6 \%$ at levels of 1.96 and $1.83 \mathrm{pg} / \mathrm{ml}$, respectively.

Serum 25-hydroxyvitamin D levels were measured by RIA using a commercially available test kit (Biosource, Inc., Nivelles, Belgium) and radioactivity was determined with a gamma counter (COBRA QUANTUM 5010; Packard Instrument Company, Meriden, CT, USA). Total (intra- and inter-assay) $\mathrm{CV}$ for control values of 22.8 and $57.9 \mathrm{ng} / \mathrm{ml}$ were 3.2 and $5.3 \%$, respectively.

Erythrocytes were directly methylated by adding boron trifluoride methanol-benzene (B1252; Sigma-Aldrich, St Louis, $\mathrm{MO}$, USA) and heating for $10 \mathrm{~min}$ at $100^{\circ} \mathrm{C}$. Fatty acid methyl esters were analysed by GC (Shimadzu 2010AF; Shimadzu Scientific Instrument, Tokyo, Japan) with a $100 \mathrm{~m}$ SP2560 capillary column (Supelco, Inc., Bellefonte, PA, USA). Fatty acids were identified by comparison to known standards (GLC-727; Nu-Check Prep, Elysian, MN, USA). In the standard, the 18:1-trans $(t)$ peak was a mixture of $18: 1 n$-12t, 18:1n-9t and $18: 1 n-7 t$, while the $18: 2 n-6 t$ peak contained $18: 2 n-6 t t$.
The omega-3 index was calculated as the sum of erythrocyte concentrations of EPA and DHA and expressed as a percentage of total fatty acids in the erythrocytes ${ }^{(11)}$. The quality control sample comprised pooled erythrocytes with a CV of $5.0 \%$.

\section{Statistical analysis}

The statistical analysis was performed using SPSS, version 12.0 (SPSS, Inc., Chicago, IL, USA). $P$ values $<0.05$ were considered statistically significant. Continuous variables were expressed using the mean and standard deviation, and proportions of nominal variables were compared using the $\chi^{2}$ test. ANOVA with the Bonferroni post hoc test was used to determine the significance of differences for continuous variables. The trend in rates for categorical variables was tested with the Mantel-Haenszel extension test. OR and $95 \%$ confidence intervals for the risk of CVD according to serum levels of 25-hydroxyvitamin D were obtained from multiple logistic regression models, after adjusting for age, sex, BMI and smoking. The lowest quartile of serum 25-hydroxyvitamin D levels was considered as a reference, and a likelihood ratio test was used to detect trends.

\section{Results}

Table 1 shows the baseline characteristics and metabolic parameters of the subjects according to serum 25-hydroxyvitamin D level quartiles. As serum 25-hydroxyvitamin D levels increased, we observed that there were significantly more men and smokers in the quartile which may be explained by the fact that most of the smokers were male. However, there were no significant differences in age, BMI, exercise, drinking and education levels between the quartiles. Although there were no significant trends with the 25-hydroxyvitamin D level quartiles, erythrocyte counts, haematocrit levels, $\mathrm{Hb}$ concentrations and aspartate transaminase:alanine transaminase ratios were significantly lower in the fourth quartile than the first quartile. $\mathrm{K}$ concentrations were significantly higher in the fourth quartile than the first quartile of serum 25-hydroxyvitamin D levels. Leucocytes count, HbA1c, glucose, albumin, $\mathrm{Na}, \mathrm{Ca}$, aspartate transaminase, alanine transaminase, total cholesterol, HDL-cholesterol, TAG, C-reactive protein, IL- 6 and TNF- $\alpha$ levels did not differ significantly between the serum 25-hydroxyvitamin D level quartiles.

Table 2 shows erythrocyte fatty acid composition according to serum 25-hydroxyvitamin D level quartiles. As serum 25-hydroxyvitamin D levels increased, erythrocyte concentrations of docosapentaenoic acid, DHA, omega-3 index and total n-3 PUFA increased significantly, while erythrocyte concentrations of stearic acid and total SFA decreased significantly, after adjusting for age, sex, BMI and smoking. Although there were no significant trends between trans-fatty acid and serum 25-hydroxyvitamin D levels, 16:1n7t was significantly higher in the first quartile of serum 25-hydroxyvitamin D levels than the fourth quartile. Consistently, partial correlation analysis showed that erythrocyte $n-3$ PUFA levels were positively correlated, while total SFA content was negatively correlated, with serum 25-hydroxyvitamin D levels (Fig. 1). 
Table 1. Characteristics and metabolic parameters of subjects by serum 25-hydroxyvitamin $D$ level quartiles $(Q)$ (Mean values and standard deviations or percentage distribution)

\begin{tabular}{|c|c|c|c|c|c|c|c|c|c|}
\hline & \multicolumn{9}{|c|}{ Serum 25-hydroxyvitamin D levels (nmol/l) } \\
\hline & \multicolumn{2}{|c|}{ Q1 ( $n$ 30) } & \multicolumn{2}{|c|}{ Q2 (n 30) } & \multicolumn{2}{|c|}{ Q3 (n 30) } & \multicolumn{2}{|c|}{ Q4 (n 30) } & \multirow[b]{3}{*}{$P$ trend $^{*}$} \\
\hline & \multicolumn{2}{|c|}{$<53 \cdot 1$} & \multicolumn{2}{|c|}{$53 \cdot 1 \leq$ to $<67 \cdot 1$} & \multicolumn{2}{|c|}{$67 \cdot 1 \leq$ to $<84 \cdot 3$} & \multicolumn{2}{|c|}{$\geq 84.3$} & \\
\hline & Mean & SD & Mean & SD & Mean & SD & Mean & SD & \\
\hline Age (years) & $55 \cdot 9$ & $13 \cdot 6$ & $53 \cdot 3$ & 11.5 & $56 \cdot 0$ & $12 \cdot 6$ & $55 \cdot 2$ & $12 \cdot 0$ & 0.840 \\
\hline BMI $\left(\mathrm{kg} / \mathrm{m}^{2}\right)$ & $24 \cdot 2$ & $4 \cdot 2$ & $24 \cdot 4$ & $2 \cdot 4$ & $23 \cdot 1$ & $2 \cdot 7$ & $24 \cdot 2$ & $2 \cdot 7$ & 0.401 \\
\hline \multicolumn{10}{|l|}{ Male } \\
\hline$n$ & 12 & & 14 & & 14 & & 20 & & \multirow{2}{*}{0.034} \\
\hline$\%$ & $40 \cdot 0$ & & $46 \cdot 6$ & & $46 \cdot 6$ & & $66 \cdot 6$ & & \\
\hline \multicolumn{10}{|l|}{ Exercise } \\
\hline$n$ & 14 & & 13 & & 14 & & 16 & & \multirow[b]{2}{*}{0.706} \\
\hline$\%$ & $46 \cdot 6$ & & $43 \cdot 3$ & & $46 \cdot 6$ & & $53 \cdot 3$ & & \\
\hline \multicolumn{10}{|l|}{ Smoking } \\
\hline$n$ & 10 & & 13 & & 14 & & 20 & & \multirow[b]{2}{*}{0.030} \\
\hline$\%$ & 33.3 & & $43 \cdot 3$ & & $46 \cdot 6$ & & $66 \cdot 6$ & & \\
\hline \multicolumn{10}{|l|}{ Drinking } \\
\hline$n$ & 13 & & 17 & & 20 & & 20 & & \multirow{2}{*}{0.080} \\
\hline$\%$ & $43 \cdot 3$ & & $56 \cdot 6$ & & $66 \cdot 6$ & & $66 \cdot 6$ & & \\
\hline \multirow{2}{*}{\multicolumn{10}{|c|}{$\begin{array}{l}\text { Education level } \\
<\text { Middle school }\end{array}$}} \\
\hline & & & & & & & & & \\
\hline$n$ & 10 & & 9 & & 9 & & 9 & & \\
\hline$\%$ & $33 \cdot 3$ & & $30 \cdot 0$ & & $30 \cdot 0$ & & $30 \cdot 0$ & & \\
\hline \multicolumn{10}{|c|}{ From middle to high school } \\
\hline$n$ & 15 & & 15 & & 17 & & 13 & & \multirow[t]{2}{*}{0.613} \\
\hline$\%$ & $50 \cdot 0$ & & $50 \cdot 0$ & & $56 \cdot 6$ & & $43 \cdot 3$ & & \\
\hline \multicolumn{10}{|l|}{$>$ High school } \\
\hline$n$ & 5 & & 6 & & 4 & & 8 & & \\
\hline$\%$ & $16 \cdot 6$ & & $20 \cdot 0$ & & $13 \cdot 3$ & & $26 \cdot 6$ & & \\
\hline Erythrocyte count $\left(10^{12} / /\right)$ & $4 \cdot 2^{\mathrm{a}}$ & $1 \cdot 3$ & $3 \cdot 5^{\mathrm{a}, \mathrm{b}}$ & $1 \cdot 8$ & $3 \cdot 9^{\mathrm{a}, \mathrm{b}}$ & 1.4 & $3 \cdot 2^{b}$ & 1.8 & 0.106 \\
\hline Haematocrit (\%) & $38 \cdot 6^{\mathrm{a}}$ & $12 \cdot 4$ & $32 \cdot 2^{\mathrm{a}, \mathrm{b}}$ & $16 \cdot 4$ & $36 \cdot 1^{\mathrm{a}, \mathrm{b}}$ & $13 \cdot 3$ & $29 \cdot 5^{\mathrm{b}}$ & $17 \cdot 1$ & 0.091 \\
\hline $\mathrm{Hb}(\mathrm{g} / \mathrm{l})$ & $139 \cdot 1^{\mathrm{a}}$ & $24 \cdot 9$ & $133 \cdot 4^{\mathrm{a}, \mathrm{b}}$ & $25 \cdot 1$ & $130 \cdot 6^{a, b}$ & $32 \cdot 1$ & $118 \cdot 4^{\mathrm{b}}$ & $43 \cdot 4$ & 0.093 \\
\hline $\mathrm{HbA1c}(\%)$ & 4.4 & $2 \cdot 8$ & 4.8 & $2 \cdot 8$ & 3.4 & 3.0 & 3.9 & 3.2 & 0.267 \\
\hline Glucose (mmol/l) & $6 \cdot 3$ & $2 \cdot 1$ & $5 \cdot 9$ & 1.6 & $6 \cdot 2$ & $2 \cdot 8$ & $6 \cdot 5$ & $4 \cdot 1$ & 0.911 \\
\hline $\mathrm{K}(\mathrm{mmol} / \mathrm{l})$ & $2 \cdot 0^{\mathrm{a}}$ & $2 \cdot 2$ & $2 \cdot 9^{\mathrm{a}, \mathrm{b}}$ & 1.8 & $2 \cdot 5^{\mathrm{a}, \mathrm{b}}$ & 1.9 & $3.1^{\mathrm{b}}$ & 1.6 & $0 \cdot 131$ \\
\hline $\mathrm{Ca}(\mathrm{mmol} / \mathrm{l})$ & 1.9 & $0 \cdot 6$ & $1 \cdot 8$ & 1.6 & $1 \cdot 8$ & $0 \cdot 8$ & $1 \cdot 6$ & 1.0 & 0.468 \\
\hline AST/ALT & $1 \cdot 6^{\mathrm{a}}$ & 0.9 & $1 \cdot 3^{\mathrm{a}, \mathrm{b}}$ & $1 \cdot 1$ & $1 \cdot 2^{\mathrm{a}, \mathrm{b}}$ & 0.7 & $1 \cdot 0^{\mathrm{b}}$ & 0.5 & 0.090 \\
\hline Total cholesterol $(\mathrm{mmol} / \mathrm{l})$ & 3.9 & $1 \cdot 7$ & $4 \cdot 1$ & $1 \cdot 2$ & 3.7 & $2 \cdot 1$ & 3.5 & $2 \cdot 0$ & 0.634 \\
\hline HDL-cholesterol (mmol/l) & $0 \cdot 8$ & 0.4 & 0.9 & 0.5 & 0.9 & 0.5 & $0 \cdot 8$ & 0.4 & 0.739 \\
\hline LDL-cholesterol (mmol/l) & $2 \cdot 3$ & $1 \cdot 2$ & $2 \cdot 1$ & 1.0 & 1.9 & 1.4 & 1.9 & $1 \cdot 2$ & 0.584 \\
\hline TAG $(\mathrm{mmol} / \mathrm{l})$ & $1 \cdot 1$ & 0.7 & $1 \cdot 2$ & 0.6 & $1 \cdot 1$ & 0.9 & 1.7 & 0.5 & 0.479 \\
\hline CRP (mg/l) & $13 \cdot 8$ & $32 \cdot 8$ & $7 \cdot 7$ & $12 \cdot 7$ & $15 \cdot 2$ & $27 \cdot 5$ & $11 \cdot 6$ & $24 \cdot 7$ & 0.697 \\
\hline IL-6 (pmol/l) & 0.2 & 0.3 & 0.2 & 0.3 & 0.2 & 0.5 & 0.2 & 0.2 & 0.820 \\
\hline TNF- $\alpha(\mathrm{pmol} / \mathrm{l})$ & 0.4 & $1 \cdot 0$ & 0.6 & $2 \cdot 2$ & $0 \cdot 1$ & 0.2 & 0.2 & 0.7 & 0.470 \\
\hline
\end{tabular}

AST, aspartate transaminase; ALT, alanine transaminase; CRP, C-reactive protein.

${ }^{\mathrm{a}, \mathrm{b}}$ Mean values with unlike letters within a row are significantly different $(P<0 \cdot 05)$.

* From a linear model.

In addition, stearic acid $(r-0 \cdot 335, P<0 \cdot 001)$, total $n-6$ PUFA ( $r$ 0.185, $P=0.048)$ and docosapentaenoic acid $(r$ 0.237, $P=0 \cdot 011)$ were correlated with serum 25-hydroxyvitamin D levels (data not shown). Multiple logistic regression analysis showed that serum 25-hydroxyvitamin D levels were not significantly associated with the risk of CVD in this population, after adjusting or not adjusting for age, sex, BMI and smoking (Table 3).

\section{Discussion}

In the present study, we detected a significant positive association between serum 25-hydroxyvitamin D and erythrocyte n-3 PUFA levels after adjusting for confounding factors; however, no association between serum 25-hydroxyvitamin D levels and risk of CVD was found in this population. Oily fish is the major dietary source of both vitamin D and $n$ - 3 PUFA, consumption of which is suggested to be protective against CVD. Previously, Lym \& Joh ${ }^{(19)}$ observed that frequent fish intake was positively associated with serum 25 -hydroxyvitamin D concentrations in healthy Korean men. Van der Meer et al. ${ }^{(20)}$ also reported that fatty fish intake was the greatest contributor to serum 25-hydroxyvitamin D levels in a multiethnic population in the Netherlands. This raises the possibility that vitamin D and $n$-3 PUFA are potential confounding factors in CVD risk. Frequency of fish intake probably resulted in a random misclassification of exposure and would attenuate any association, and thus tissue levels of $n$-3 PUFA could be a better indicator of fish intake. The present study was the first to investigate the 
Table 2. Erythrocyte fatty acid composition of subjects by serum 25-hydroxyvitamin $D$ level quartiles $(Q)$ (Mean values and standard deviations)

\begin{tabular}{|c|c|c|c|c|c|c|c|c|c|}
\hline \multirow[b]{4}{*}{ Fatty acids } & \multicolumn{8}{|c|}{ Serum 25-hydroxyvitamin D levels ( $\mathrm{nmol} / \mathrm{l})$} & \multirow[b]{4}{*}{$P$ trend } \\
\hline & \multirow{2}{*}{\multicolumn{2}{|c|}{$\begin{array}{c}\text { Q1 (n 30) } \\
<53 \cdot 1\end{array}$}} & \multirow{2}{*}{\multicolumn{2}{|c|}{$\frac{\mathrm{Q} 2(n 30)}{53 \cdot 1 \leq \text { to }<67 \cdot 1}$}} & \multirow{2}{*}{\multicolumn{2}{|c|}{$\frac{\mathrm{Q} 3(n \mathrm{n}))}{67 \cdot 1 \leq \text { to }<84 \cdot 3}$}} & \multirow{2}{*}{\multicolumn{2}{|c|}{$\begin{array}{c}\text { Q4 (n 30) } \\
\geq 84.3\end{array}$}} & \\
\hline & & & & & & & & & \\
\hline & Mean & SD & Mean & SD & Mean & SD & Mean & SD & \\
\hline $14: 0$ & 0.4 & 0.2 & 0.3 & $0 \cdot 1$ & 0.4 & 0.2 & 0.4 & 0.1 & 0.497 \\
\hline $16: 0$ & 24.9 & $5 \cdot 5$ & 23.4 & 3.5 & $23 \cdot 2$ & $3 \cdot 2$ & $23 \cdot 2$ & $2 \cdot 2$ & 0.247 \\
\hline $18: 0$ & $19 \cdot 9^{\mathrm{a}}$ & 4.9 & $18 \cdot 1^{b}$ & $2 \cdot 7$ & $17 \cdot 7^{\mathrm{b}}$ & 3.3 & $16 \cdot 9^{b}$ & $2 \cdot 0$ & 0.010 \\
\hline Total SFA & $45 \cdot 6^{\mathrm{a}}$ & $10 \cdot 2$ & $42 \cdot 2^{a, b}$ & 5.9 & $41 \cdot 7^{b}$ & $5 \cdot 7$ & $40 \cdot 9^{b}$ & $3 \cdot 1$ & 0.044 \\
\hline $16: 1 n-7$ & 0.6 & 0.3 & 0.6 & 0.3 & 0.7 & 0.6 & 0.7 & 0.4 & 0.853 \\
\hline $18: 1 n-9$ & $14 \cdot 2$ & 1.9 & $13 \cdot 7$ & $2 \cdot 1$ & $13 \cdot 9$ & $2 \cdot 6$ & $14 \cdot 6$ & $2 \cdot 3$ & 0.441 \\
\hline Total MUFA & $15 \cdot 7$ & $2 \cdot 1$ & $15 \cdot 2$ & $2 \cdot 4$ & $15 \cdot 7$ & 3.2 & $16 \cdot 1$ & $2 \cdot 4$ & 0.602 \\
\hline $18: 2 n-6$ & $10 \cdot 6$ & $2 \cdot 9$ & $10 \cdot 6$ & $2 \cdot 4$ & $10 \cdot 6$ & $2 \cdot 7$ & $10 \cdot 6$ & $2 \cdot 4$ & 1.000 \\
\hline $20: 4 n-6$ & $11 \cdot 3$ & $4 \cdot 6$ & $13 \cdot 0$ & 3.0 & $12 \cdot 7$ & $3 \cdot 2$ & $13 \cdot 0$ & $1 \cdot 7$ & 0.170 \\
\hline Total $n-6$ PUFA & $26 \cdot 1$ & $7 \cdot 3$ & 28.4 & 4.8 & $27 \cdot 9$ & 4.4 & 28.3 & 3.2 & 0.272 \\
\hline $18: 3 n-3$ & 0.5 & 0.7 & 0.6 & 0.4 & 0.6 & 0.8 & 0.8 & $1 \cdot 3$ & 0.506 \\
\hline $20: 5 n-3$ & 1.7 & 1.6 & 1.5 & 0.7 & 1.9 & 1.4 & 1.8 & 1.0 & 0.746 \\
\hline $22: 5 n-3$ & $2 \cdot 1^{\mathrm{a}}$ & $1 \cdot 0$ & $2 \cdot 5^{\mathrm{a}, \mathrm{b}}$ & 0.7 & $2 \cdot 6^{\mathrm{b}}$ & 0.8 & $2 \cdot 8^{\mathrm{b}}$ & 0.5 & 0.027 \\
\hline $22: 6 n-3$ & $6 \cdot 8^{\mathrm{a}}$ & $2 \cdot 8$ & $8 \cdot 0^{\mathrm{b}}$ & $2 \cdot 2$ & $8 \cdot 1^{\mathrm{b}}$ & $2 \cdot 4$ & $8 \cdot 1^{\mathrm{b}}$ & 1.8 & 0.020 \\
\hline Omega-3 index & $8 \cdot 6^{\mathrm{a}}$ & 3.7 & $9 \cdot 6^{a, b}$ & $2 \cdot 6$ & $10 \cdot 0^{\mathrm{b}}$ & $3 \cdot 1$ & $10 \cdot 0^{\mathrm{b}}$ & $2 \cdot 4$ & 0.048 \\
\hline Total $n$-3 PUFA & $11 \cdot 3^{a}$ & $5 \cdot 0$ & $12 \cdot 8^{\mathrm{a}, \mathrm{b}}$ & $3 \cdot 4$ & $13 \cdot 3^{b}$ & $4 \cdot 0$ & $13 \cdot 7^{\mathrm{b}}$ & $2 \cdot 8$ & 0.013 \\
\hline $16: 1 n-7 t$ & $0.3^{\mathrm{a}}$ & 0.2 & $0 \cdot 3^{a, b}$ & 0.2 & $0.3^{a, b}$ & 0.3 & $0.2^{b}$ & 0.1 & 0.118 \\
\hline $18: 1 n-9 t$ & 0.4 & 0.2 & 0.5 & 0.2 & 0.5 & 0.5 & 0.4 & 0.3 & 0.639 \\
\hline $18: 2 n-6 t$ & $0 \cdot 2$ & 0.1 & $0 \cdot 2$ & $0 \cdot 1$ & $0 \cdot 2$ & 0.1 & $0 \cdot 2$ & 0.1 & 0.612 \\
\hline Total trans-fatty acids & $1 \cdot 1$ & 0.4 & $1 \cdot 1$ & 0.5 & $1 \cdot 1$ & 0.8 & 0.8 & 0.4 & 0.254 \\
\hline
\end{tabular}

a,b Mean values with unlike letters within a row are significantly different.

*From a linear model after adjusting for age, sex, BMI and smoking.

relationship between tissue levels (erythrocytes) of $n-3$ PUFA and serum 25-hydroxyvitamin D levels.

Although the exact mechanisms by which an adequate vitamin D status may protect against CVD are not fully understood, experimental studies indicate that vitamin $\mathrm{D}$ is one of the most potent chemicals for suppressing the renin-angiotensin system and thus for regulating blood pressure $^{(21)}$. In addition, vitamin D may influence vascular function and the development or progression of atherosclerosis. Vitamin D receptors have a broad tissue distribution that includes vascular smooth muscle cells $^{(22)}$, macrophages ${ }^{(23)}$ and lymphocytes ${ }^{(24)}$. Vitamin D induces prostacyclin in vascular smooth muscle cells, which prevents thrombus formation, cell adhesion and smooth muscle cell proliferation ${ }^{(25)}$. Vitamin D suppresses pro-inflammatory cytokines, including IL and TNF- $\alpha$ in vitro and in vivo ${ }^{(26)}$. However, there was no association between 25-hydroxyvitamin D levels and cytokines in the present study. The lack of association may be partly due to the elevated inflammatory profile as a result of acute trauma, such as heart attack and stroke in the subjects.

There is limited epidemiological evidence of an association between vitamin $\mathrm{D}$ and the risk of CVD. In the Health
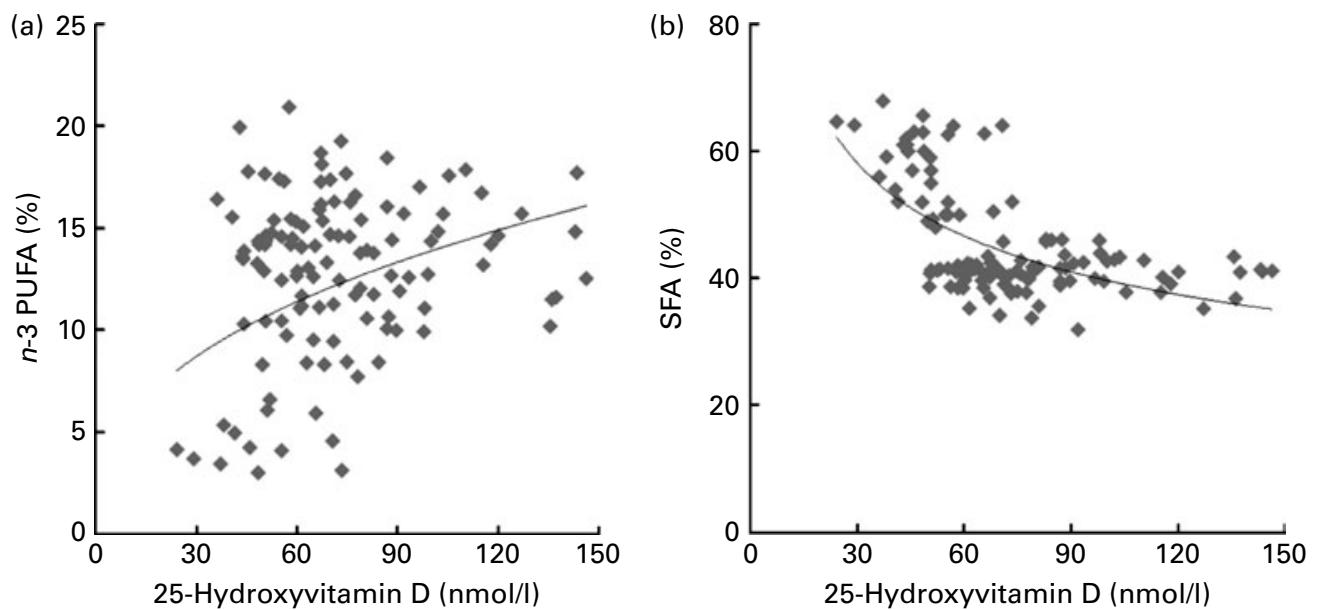

Fig. 1. Pearson's correlation coefficients between serum 25-hydroxyvitamin D concentrations and levels of total (a) $n$-3 PUFA ( $r$ 0.215; $P=0.021)$ and (b) SFA $(r-0.263 ; P=0.004)$ in erythrocytes after adjusting for age, sex, BMI and smoking. 
Table 3. Association of serum 25-hydroxyvitamin D levels with risk of CVD by multivariable regression analysis

(Odds ratios and $95 \%$ confidence intervals) $^{\star}$

\begin{tabular}{lcllll}
\hline & \multicolumn{5}{c}{ Serum 25-hydroxyvitamin D levels (nmol/l) } \\
\cline { 2 - 6 } Variables & $<53.1$ & $53.1 \leq$ to $<66.6$ & $66.6 \leq$ to $<80.8$ & $\geq 80.8$ & $P$ trend \\
\hline Cases $(n)$ & 15 & 18 & 13 & 14 & NA \\
Controls $(n)$ & 15 & 15 & 15 & 15 & \\
Model 1 & & & & 0.93 & 0.493 \\
$\quad$ OR & 1 & 1.19 & 0.80 & $0.34,2.59$ & \\
$\quad$ 95\% Cl & & $0.41,3.45$ & $0.28,2.27$ & 0.80 & 0.334 \\
Model 2 & 1 & 1.14 & 0.83 & $0.27,2.33$ & \\
$\quad$ OR & & $0.38,3.40$ & $0.28,2.43$ & & \\
95\% Cl & & &
\end{tabular}

Professionals Follow-up Study, men with high circulating levels of 25-hydroxyvitamin D had half the risk of myocardial infarction as men with vitamin D insufficiency ${ }^{(4)}$. The MinFinland Health Study ${ }^{(5)}$ showed that low serum 25-hydroxyvitamin $\mathrm{D}$ levels might have a more important role in the prevention of CVD, particularly cerebrovascular disease. Similarly, a study of German adults who were undergoing elective cardiac catheterisation showed a twofold risk of CVD death among persons in the lowest quartile of baseline vitamin D levels compared with those in the highest quartile ${ }^{(6)}$. However, vitamin D deficiency was associated with an increased risk of CVD in hypertensive subjects, but not in those without hypertension in the Framingham Offspring Study cohort ${ }^{(27)}$. The Third National Health and Nutrition Examination Survey $^{(7)}$ also did not find a statistically significant association between vitamin D status and the risk of CVD.

There are a few plausible explanations for these inconsistent findings. First, the Diet and Reinfarction Trial ${ }^{(14)}$ has shown that oily fish intake significantly reduced the risk of cardiac death and CVD events, and our previous studies involving a similar population suggested that high erythrocyte $n$-3 PUFA levels were associated with the risk of myocardial infarction $^{(12)}$ and stroke ${ }^{(13)}$. However, previous studies have not investigated the association of vitamin $\mathrm{D}$ and $n-3$ PUFA with CVD, the potential confounding factors. Second, optimal levels of serum 25-hydroxyvitamin D levels for CVD protection are not known, but relatively high concentrations of serum 25-hydroxyvitamin $\mathrm{D}(>75 \mathrm{nmol} / \mathrm{l})$ are required to maintain normal parathyroid hormone levels and even higher levels $(83-121 \mathrm{nmol} / \mathrm{l})$ are suggested to be desirable for preventing cancer ${ }^{(28)}$. The mean levels of serum 25 -hydroxyvitamin $\mathrm{D}$ in the present study were approximately of the same order of magnitude as those previously found in the general Korean population(29), but somewhat higher than those generally observed in American ${ }^{(4,7)}$, German ${ }^{(6)}$ and Finnish $^{(5)}$ subjects. It is noteworthy that a vitamin D and CVD association was observed in a population with lower vitamin D levels. Third, serum 25-hydroxyvitamin D levels measured at a single point in time reflect only recent exposure rather than long-term exposure. A single serum measurement could be a useful tool in epidemiological studies, but such a measurement fails to take into account the intra-individual seasonal variation in serum 25-hydroxyvitamin D levels. To account for seasonality as a potential confounder, we included twenty cases and twenty controls with blood samples drawn during winter; the rest were drawn between April and November.

Interestingly, we found that erythrocyte SFA levels were negatively associated with serum 25-hydroxyvitamin D concentrations. SFA provide about $50 \%$ of the fatty acids found in meat ${ }^{(30)}$, and Welch et al. ${ }^{(31)}$ reported that non-fish-eating meat-eaters had lower intakes of $n$ - 3 PUFA compared with fish-eaters. Thus, meat-eaters may have higher SFA and lower $n$-3 PUFA intake, suggesting that differences in diet could partly explain the negative association between SFA and vitamin $\mathrm{D}$ in the present study.

A limitation of the present study was the small sample size. We also acknowledge that the cross-sectional design of the present study limits the ability to understand causal inference, and therefore does not allow for the establishment of a cause-effect relationship between vitamin D and the risk of CVD. Differences in the selection criteria and the demographics of the study population may be responsible for our inconsistent findings, and the present findings may be limited to Koreans and not applicable to other groups or other geographic areas. While the homogeneity of our sample may limit the external validity of the present findings, it minimises the potential for residual confounding by unmeasured characteristics.

In conclusion, the present study demonstrates for the first time, to our knowledge, that serum 25-hydroxyvitamin D levels are positively associated with tissue levels of $n-3$ PUFA. However, we failed to show a significant association between serum 25-hydroxyvitamin $D$ levels and risk for CVD in this population. Further investigations involving a greater number of subjects from different populations with repeated measurements of vitamin D status are warranted. To demonstrate a possible link between vitamin D status and risk of CVD, large clinical trials that adjust for dietary intake, sun exposure and the effects of $n-3$ PUFA are needed.

\section{Acknowledgements}

This research was supported by the Basic Science Research Program through the National Research Foundation of 
Korea, funded by the Ministry of Education, Science and Technology (2010-0008656). The authors state that there are no conflicts of interest. Y. P. was the principal investigator for this project and wrote the manuscript, and M. K. conducted laboratory and statistical analyses. The authors thank Dr Hyengjoong Yi, Dr Hyun Young Kim and Dr Jaeung Lee at the Hanyang University Hospital for their assistance in recruiting patients and collecting medical information.

\section{References}

1. Holick MF (2007) Vitamin D deficiency. N Engl J Med 357, 266-281.

2. Michos ED \& Melamed ML (2008) Vitamin D and cardiovascular disease risk. Curr Opin Clin Metab Care 11, 7-12.

3. Zittermann A, Schleithoff SS \& Koerfer R (2005) Putting cardiovascular disease and vitamin $\mathrm{D}$ insufficiency into perspective. Br J Nutr 94, 483-492.

4. Giovannucci E, Liu Y, Hollis BW, et al. (2008) 25-Hydroxyvitamin $\mathrm{D}$ and risk of myocardial infarction in men. A prospective study. Arch Intern Med 168, 1174-1180.

5. Kilkkinen A, Knekt P, Aro A, et al. (2009) Vitamin D status and the risk of cardiovascular disease death. Am J Epidemiol 170, 1032-1039.

6. Dobnig H, Pilz S, Scharnagl H, et al. (2008) Independent association of low serum 25-hydroxyvitmin D and 1,25-dihydroxyvitamin D levels with all cause and cardiovascular mortality. Arch Intern Med 168, 1340-1349.

7. Melamed ML, Michos ED, Post W, et al. (2008) 25-Hydroxyvitamin D levels and the risk of mortality in the general population. Arch Intern Med 168, 1629-1637.

8. Martins D, Wolf M, Pan D, et al. (2007) Prevalence of cardiovascular risk factors and the serum levels of 25-hydroxyvitmain $\mathrm{D}$ in the United States: data from the Third National Health and Nutrition Examination Survey. Arch Intern Med 167, 1159-1165.

9. Hsia J, Heiss G, Ren H, et al. (2007) Calcium/vitamin D supplementation and cardiovascular events. Circulation 115, 846-854.

10. Newhouser ML, Wassertheil-Smoller S, Thomson C, et al. (2009) Multivitamin use and risk of cancer and cardiovascular disease in the Women's Health Initiative cohorts. Arch Intern Med 169, 294-304.

11. Harris WS \& Von Schacky C (2004) The Omega-3 Index: a new risk factor for death from coronary heart disease? Prev Med 39, 212-220.

12. Park Y, Lim J, Lee J, et al. (2009) Erythrocyte fatty acid profiles can predict acute non-fatal myocardial infarction. Br J Nutr 102, 1255-1361.

13. Park Y, Park S, Yi HJ, et al. (2009) Low level of $n$-3 polyunsaturated fatty acids in erythrocytes is a risk factor for both acute ischemic and hemorrhagic stroke in Koreans. Nutr Res 29, 825-830.

14. Burr ML, Fehily AM, Gilbert JF, et al. (1989) Effects of changes in fat, fish, and fibre intakes on death and myocardial reinfarction: diet and reinfarction trial (DART). Lancet 334, 757-761.

15. Marchioli R, Barzi F, Bomba E, et al. (2002) Early protection against sudden death by $n-3$ polyunsaturated fatty acids after myocardial infarction: time-course analysis of the results of the
Gruppo Italiano per lo Studio della Sopravvivenza nell'Infarto Miocardico (GISSI)-Prevenzione. Circulation 105, 1897-1903.

16. Yokoyama M, Origasa H, Matsuzaki M, et al. (2007) Effects of eicosapentaenoic acid on major coronary events in hypercholesterolaemic patients (JELIS): a randomized open-label, blinded endpoint analysis. Lancet 369, 1090-1098.

17. Korean National Health and Nutrition Examination Office (2005) Report on the Korean National Health and Nutrition Examination Survey. Seoul, Korea: Korean National Health and Nutrition Examination Office.

18. Nogi A, Yang J, Limei L, et al. (2007) Plasma n-3 polyunsaturated fatty acid and cardiovascular disease risk factors in Japanese, Korean and Mongolian works. J Occup Health 49, 205-216.

19. Lym YL \& Joh HK (2009) Serum 25-hydroxyvitamin D3 is related to fish intake and exercise in Korean adult men. Asia Pac J Clin Nutr 18, 372-376.

20. van der Meer IM, Boeke AJ, Lips P, et al. (2008) Fatty fish and supplements are the greatest modifiable contributors to the serum 25-hydroxyvitamin D concentration in a multiethnic population. Clin Endocrinol (Oxf) 68, 466-472.

21. Li YC, Kong J, Wei M, et al. (2002) 25-Dihydroxyvitamin D(3) is a negative endocrine regulator of the rennin-angiotensin system. J Clin Invest 110, 229-238.

22. Carthy EP, Yamashita W, Hsu A, et al. (19889) 1,25-Dihydroxyvitamin D3 and rat vascular smooth muscle cell growth. Hypertension 13, 954-959.

23. Shioi A, Katagi M, Okuno Y, et al. (2002) Induction of bonetype alkaline phosphatase in human vascular smooth muscle cells: roles of tumor necrosis factor-alpha and oncostatin $M$ derived from macrophages. Circ Res 91, 9-16.

24. Rigby WF, Denome S \& Fanger MW (1987) Regulation of lymphokine production and human T lymphocyte activation by 1,25-dihydroxyvitamin D3. Specific inhibition at the level of messenger RNA. J Clin Invest 79, 1659-1664.

25. Wakasugi M, Noguchi T, Inoue $M$, et al. (1991) Vitamin $D_{3}$ stimulates the production of prostacyclin by vascular smooth muscle cells. Prostaglandins 42, 127-136.

26. Zittermann A \& Koerfer R (2008) Protective and toxic effects of vitamin D on vascular calcification: clinical implications. Mol Aspects Med 29, 423-432.

27. Wang TJ, Pencina MJ, Booth SL, et al. (2008) Vitamin D deficiency and risk of cardiovascular disease. Circulation 117, 503-511.

28. Bischoff-Ferrari HA, Giovannucci E, Willett WC, et al. (2006) Estimation of optimal serum concentrations of 25-hydroxyvitamin D for multiple health outcomes. Am J Clin Nutr 84, $18-28$.

29. Kim MK, Kang IM, Oh WK, et al. (2010) The association of serum vitamin D level with presence of metabolic syndrome and hypertension in middle-aged Korean subjects. Clin Endocrinol (Oxf) 73, 330-338.

30. National Health, Medical Research Council (2006) Nutrient Reference Values for Australia and New Zealand. Australia: Department of Health and Ageing.

31. Welch AA, Shakya-Shrestha S \& Lentjes MA (2010) Dietary intake and status of $n-3$ polyunsaturated fatty acids in a population of fish-eating and non-fish-eating meat-eaters, vegetarians, and vegans and the precursor-product ratio of \{alpha\}-linolenic acid to long-chain $n-3$ polyunsaturated fatty acids: results from the EPIC-Norfolk cohort. Am J Clin Nutr 92, 1040-1051. 